\title{
Volatility Spillover and Multivariate Volatility Impulse Response Analysis of GFC News Events ${ }^{1}$
}

\author{
David E. Allen ${ }^{1}$ Michael McAleer ${ }^{2 *}$, Robert Powell ${ }^{3}$ and Abhay K.Singh ${ }^{4}$ \\ ${ }^{1}$ School of Mathematics and Statistics, University of Sydney and School of Business, University of \\ South Australia, Australia \\ ${ }^{2}$ Department of Quantitative Finance, National Tsing Hua University, Taiwan \\ ${ }^{3}$ School of Business and Law, Edith Cowan University, Australia \\ ${ }^{4}$ School of Business and Law, Edith Cowan University, Australia \\ ”michael.mcaleer@gmail.com
}

\begin{abstract}
This paper applies two measures to assess spillovers across markets: the Diebold Yilmaz (2012) Spillover Index and the Hafner and Herwartz (2006) analysis of multivariate GARCH models using volatility impulse response analysis. We use two sets of data, daily realized volatility estimates taken from the Oxford Man RV library, running from the beginning of 2000 to October 2016, for the S\&P500 and the FTSE, plus ten years of daily returns series for the New York Stock Exchange Index and the FTSE 100 index, from 3 January 2005 to 31 January 2015. Both data sets capture both the Global Financial Crisis (GFC) and the subsequent European Sovereign Debt Crisis (ESDC). The spillover index captures the transmission of volatility to and from markets, plus net spillovers. The key difference between the measures is that the spillover index captures an average of spillovers over a period, whilst volatility impulse responses (VIRF) have to be calibrated to conditional volatility estimated at a particular point in time. The VIRF provide information about the impact of independent shocks on volatility. In the latter analysis, we explore the impact of three different shocks, the onset of the GFC, which we date as 9 August 2007 (GFC1). It took a year for the financial crisis to come to a head, but it did so on 15 September 2008, (GFC2). The third shock is 9 May 2010. Our modelling includes leverage and asymmetric effects undertaken in the context of a multivariate GARCH model, which are then analysed using both BEKK and diagonal BEKK (DBEKK) models. A key result is that the impact of negative shocks is larger, in terms of the effects on variances and covariances, but shorter in duration, in this case a difference between three and six months.
\end{abstract}

Keywords:Spillover Index, Volatility Impulse Response Functions (VIRF), BEKK, DBEKK, Asymmetry, GFC, ESDC.

JEL: C22, C32, C58, G32.

\section{Introduction}

The similarities between GARCH and VARMA-type models provide a foundation for the approach to generalize impulse response analysis, as introduced by Sims (1980), to the analysis of shocks in financial volatility. Previous alternative approaches in the literature have been made towards tracing the impact of various types of shocks through time (see, for example, Koop et al. (1996), Engle and $\mathrm{Ng}$, (1993), Gallant et al. (1993), and Lin (1997)). Koop et al. (1996) defined generalized impulse response functions for the conditional expectation using the mean of the response vector conditional on history and a current shock, as compared with a baseline that conditions only on historical innovations. The two metrics we use to capture spillovers in this paper build upon these approaches.

\footnotetext{
${ }^{1}$ For financial support, the first author wishes to thank the Australian Research Council and the second author wishes to acknowledge the Australian Research Council and the National Science Council, Ministry of Science and Technology (MOST), Taiwan. The authors are grateful to Tom Doan and Estima for helpful assistance with RATS coding. We are grateful to the two anonymous reviewers for very helpful comments and suggestions. McAleer is University Distinguished Research Professor at the Institute for Social and Economic Sciences (ISES), Dhurakij Pundit University (DPU), Bangkok, Thailand.
} 
Diebold and Yilmaz $(2009,2012)$ develop measures of return and volatility spillovers based on vector autoregressive (VAR) models. The Diebold and Yilmaz (2012) variant of their measure is based on generalized impulse responses and captures both directional and net spillovers between markets. The first set of analyses in this paper is based on the application of these metrics to analyse daily realized volatility (RV) metrics taken from the Oxford-Man Institute of Quantitative Finance Realized Library for the S\&P500 and the FTSE index (See Gerd et al., (2009)).

The Diebold and Yilmaz Spillover Index method has attracted some attention in the literature. Kloessner and Wagner (2012) present an algorithm, to explore the true range of the (2009) spillover index, in which the impulse response functions depended on the ordering of variables in the VAR. However, this issue has been avoided in the Diebold and Yilmaz (2012) measure. Alter and Beyer (2013) explore the dynamics of the European Sovereign Debt Crisis using a metric based on the Spillover Index. Diebold and Yilmaz $(2014,2016)$ have expanded their method to measure financial firm interconnectedness.

The second set of analyses feature Hafner and Herwartz's (2006) Volatility Impulse Response Functions (VIRFs) which also extend the generalized impulse response functions framework provided by Koop et al. (1996). Their approach is novel in that VIRF explores the conditional variance rather than the conditional mean. Given that GARCH models can be viewed as being linear in the squared innovations, and that multivariate GARCH models are known to have a VARMA representation with non-Gaussian errors, Hafner and Hewartz (2006) adopt this particular structure to calculate conditional expectations of volatility analytically in their VIRF analysis.

Panopoulou and Pantelidis (2009) examine volatility transmissions between the U.S. and the rest of the G-7 countries using daily stock market return data and report that the linkages between the markets had changed substantially with national markets becoming more interdependent. They provide evidence of direct volatility spillovers, running mainly from the US and point to more rapid information transmission during the later years of their study. Their analysis is the closest in spirit to the current study, but they do not examine the impact of asymmetric shocks in their GARCH framework or employ the Diebold and Yilmaz (2012) Spillover Index analysis. Jin et al., (2012), use VIRF to analyse the transmission of shocks in crude oil markets, whilst Le Pen and Sevi (2010), undertake a similar analysis of electricity markets. Ohlsen et al., (2014) employ VIRF analysis to explore the relationship between energy and equity markets.

More generally, in the GARCH literature there has been a longstanding concern with modelling volatility transmission. An early study by Koutmos and Booth (1995) examined price volatility spillovers for the US, the UK and Japan in the context of a multivariate EGARCH model which permitted the capture of possible asymmetries in the volatility transmission mechanism. These authors found evidence of price spillovers, and extensive and reciprocal second moment interactions, which were asymmetric, i.e. negative innovations in a given market increased volatility in the next market to trade more than positive innovations. We further explore this issue in the current paper. Furthermore, Ross (1989), suggested that under appropriate conditions, the variance of price change equals the rate of information flow, and thus provided a direct link between the second moment and the flow of information, in an arbitrage free economy. In a continuation of this logic, Engle et al., (1990) noted that a possible explanation for ARCH effects and an explanation of the phenomenon of volatility clustering, must lie either in the arrival process of news, or in market dynamics in response to the news. If information comes in clusters, then the asset returns or prices may exhibit ARCH behaviour, even if the market perfectly and instantaneously adjusts to the news. The current paper follows in this tradition and uses impulse response analysis to analyse the transmission of shocks across markets.

In our Generalized VIRF (GVIRF), we consider three major news events which act as shocks to the volatility of our two series. The onset of the GFC, which we date as 9 August 2007 (GFC1), began with the seizure in the banking system precipitated by BNP Paribas announcing that it was ceasing activity in three hedge funds that specialised in US mortgage debt. It took one year for the financial 
crisis to come to a head, but it did so on 15 September 2008 when the US government allowed the investment bank Lehman Brothers to go bankrupt (GFC2). The date 9 May 2010 marked the point at which the focus of concern switched from the private sector to the public sector. By the time the IMF and the European Union announced they would provide financial help to Greece, the issue was no longer the solvency of banks but the solvency of governments, and this marks the onset of the European Sovereign Debt Crisis (ESDC).

The major difference between the two approaches is that the first utilises a VAR approach to jointly analyse a time-series of the daily RV series for the two markets, as represented by the S\&P500 and the FTSE. The method features an analysis of the average of the RV series for the two markets and the metrics applied capture spillovers to and from the two markets and the net spillovers. The VIRF analysis is developed in the context of a multivariate GARCH approach, incorporating assymetric effects, and featuring analysis of the impulse responses of the conditional volatility series. Given that volatility is conditional, it makes sense to condition the model on volatility at a given point in time, rather than an average. Hence, we use three different points in time, or subsamples, in our basic series to capture impacts at the onset of the GFC, the height of the GFC, and the beginning of subsequent European Sovereign debt crisis.

The remainder of the paper is as follows. In Section 2 the research methods and data are discussed, including the Spillover Index, volatility impulse response functions, multivariate GARCH models, the regularity conditions for BEKK and diagonal BEKK (DBEKK) models, the triangular, Hadamard and full BEKK models, and diagonal and scalar BEKK models. The empirical results are discussed in Section 3, and some concluding remarks are given in Section 4.

\section{Research Methods and Data}

We use two different parametric approaches to explore the transmission of volatility shocks across markets; the Diebold and Yilmaz (2009, 2012) Spillover Index and the Hafner and Herwartz (2006) multivariate volatility impulse response analysis. The next sub-sections introduce the methods used.

\subsection{Spillover index}

Diebold and Yilmaz (2009) develop a measure of return and volatility spillovers based on vector autoregressive (VAR) models in the broad tradition of Engle, Ito and Lin (1990). They concentrate on variance decompositions, and they demonstrate how it is possible to aggregate spillover effects across markets, capturing a great deal of information into a single spillover measure. They construct their measure using variance decompositions associated with an $\mathrm{N}$ variable VAR. They proceed by taking each asset $i$, and adding the shares of its forecast error variance coming from shocks to asset $j$, for all $j \neq i$, and then they add across all $i, i=1, \ldots, N$. The variance decompositions allow permit them to split the forecast error variances of each variable into parts attributable to the various system shocks. They aggregate and conduct a spillover index. A drawback of the Diebold and Yilmaz (2009) spillover index is that it relies on Cholesky-factor identification of VARs, meaning that the resulting variance decompositions can be dependent on variable ordering. In addition their (2009) measure captures total spillovers but not directional spillovers. Diebold and Yilmaz (2012) extend their (2009) metric to make it invariant on ordering, by using generalised impulse response functions, and construct it in a manner that captures directional spillovers. They proceed in the following manner.

They consider a covariance stationary N-variable $\operatorname{VAR}(\mathrm{p}), x_{i}=\sum_{i=1}^{p} \Phi_{i} x_{i-1}+\varepsilon_{i}$, where, $\varepsilon \sim(0, \Sigma)$ is a vector of i.i.d. disturbances. The moving average representation is $x_{i}=\sum_{i=0}^{\infty} A_{i} \varepsilon_{t-i}$, where the $N \times N$ coefficient matrices $A_{i}$ obey the recursion $A_{i}=\Phi_{1} A_{i-1}+\Phi_{2} A_{i-2}+\cdots+\Phi_{p} A_{i-p}$, with $A_{0}$ an $N \times N$ identity matrix and $A_{i}=0$ for $i<0$. 
The Diebold and Yilmaz (2009, 2012) spillover index measures use variance decompositions, which permit them to decompose the forecast error variances of each variable into parts attributable to the various system shocks. The innovation in Diebold and Yilmaz (2012) is that they employ a generalized VAR framework in the manner of Koop, Pesaran and Potter (1996) and Pesaran and Shin (1998). The generalized framework permits correlated shocks but treats them appropriately using the historically observed distribution of the errors.

Diebold and Yilmaz (2012) define own variance shares as the fraction of the H-step-ahead error variances in forecasting $x_{i}$ due to shocks to $x_{i}$, for $i=1,2, \ldots, N$, and cross variance shares, or spillovers, as the fractions of the H-step-ahead error variances in forecasting $x_{i}$ resulting from shocks to $x_{j}$, for $\mathrm{i}, j=1,2, \ldots, N$, such that $i \neq j$.

Diebold and Yilmaz (2012) write the generalised H-step-ahead forecast error variance decompositions by $\theta_{i j}^{g}(H)$, for $\mathrm{H}=1,2, \ldots$, resulting in

$$
\theta_{i j}^{g}(H)=\frac{\sigma_{i i}^{-1} \sum_{h=0}^{H-1}\left(e_{i}^{\prime} A_{h} \sum e_{j}\right)^{2}}{\sum_{h=0}^{H-1}\left(e_{i}^{\prime} A_{h} \sum A_{h}^{\prime}\right)} .
$$

Where $\sum$ is the variance matrix for for the error vector $\varepsilon, \sigma_{i i}$ is the standard deviation of the error term for the ith equation and $e_{i}$ is the selection vector with one as the $\mathrm{i}$ th element and zero otherwise. Given that they have used generalised impulse response functions the sum of the elements of each row of the variance decomposition table is not equal to $1: \sum_{j=1}^{N} \theta_{i j}^{g} \neq 1$.

They use the information available in the variance decomposition matrix for the construction of the spillover index by normalizing each entry of the variance decomposition matrix by the row sum as:

$$
\tilde{\theta}_{i j}^{g}(H)=\frac{\theta_{i j}^{g}(H)}{\sum_{j=1}^{N} \theta_{i j}^{g}(H)} .
$$

In this construction, $\sum_{j=1}^{N} \tilde{\theta}_{i j}^{g}(H)=1$ and $\sum_{i, j=1}^{N} \tilde{\theta}_{i j}^{g}(H)=N$.

Deibold and Yilmaz (2012) then proceed to construct a total volatility spillover index as:

$$
S^{g}(H)=\frac{\sum_{\substack{i, j=1 \\ i \neq j}}^{N} \tilde{\theta}_{i j}^{g}(H)}{\sum_{i, j=1}^{N} \tilde{\theta}_{i j}^{g}(H)} \cdot 100=\frac{\sum_{\substack{i, j=1 \\ i \neq j}}^{N} \tilde{\theta}_{i j}^{g}(H)}{N} .100 .
$$

They further construct a directional spillover measure to illuminate how volatility spills across from different assets or asset classes. They do this by using the normalized elements of the generalized variance decomposition matrix. Their measure of directional volatility spillover received by market $i$ from other markets $j$ as:

$$
S_{i \cdot}^{g}(H)=\frac{\sum_{j=1}^{N} \tilde{\theta}_{i j}^{g}(H)}{\sum_{j=1}^{N} \tilde{\theta}_{i j}^{g}(H)} \cdot 100 .
$$

By contrast directional volatility spillovers transmitted by market $\mathrm{i}$ to market $\mathrm{j}$ as:

$$
S_{i \cdot}^{g}(H)=\frac{\sum_{j=1}^{N} \tilde{\theta}_{j i}^{g}(H)}{\sum_{j=1}^{N} \tilde{\theta}_{i j}^{g}(H)} \cdot 100 .
$$

Finally, Diebold and Yilmaz (2012) compute net spillovers from market i to all other markets j as: 


$$
S_{i}^{g}(H)=S_{\cdot i}^{g}(H)-S_{i \cdot}^{g}(H) .
$$

The net volatility spillover is the difference between gross volatility shocks transmitted to and gross volatility shocks received from all other markets.

We use these measures and the multivariate volatility impulse response functions introduced in the next subsection.

\subsection{Multivariate volatility impulse response functions}

Hafner and Herwartz (2006) develop their model by letting $\varepsilon_{t}$ denote an $N$-dimensional random vector, so that:

$\varepsilon_{t}=P_{t} \xi_{t}$

where $P_{t} P_{t}^{\prime}=\sum_{t}$ and $\xi_{t}$ denotes an iid random vector of dimension $N$, with independent components, mean zero and identity covariance matrix. Hafner and Herwartz assume that $\sum_{t}$ is measurable with respect to the information set available at time $t-1, F_{t-1}$. Equation (1) implies that $E\left[\varepsilon_{t} \mid F_{t-1}\right]=0$, and $\operatorname{Var}\left[\varepsilon_{t} \mid F_{t-1}\right]=\sum_{t}{ }^{\cdot}$ They note that ${ }^{\varepsilon_{t}}$ could be the error of a VARMA process. If $\varepsilon_{t}$ is a multivariate GARCH process, then equation (1) may be called a strong GARCH model, according to Drost and Nijman (1993). This is convenient because it permits the modelling of news events as appearing in the iid innovation, $\xi_{t}$. They identify $\xi_{t}$ by assuming that $P_{t}$ is a lower triangular matrix, which permits the use of a Choleski decomposition of $\sum_{t} \cdot$ They also use the fact that independent news can often be identified by means of a Jordan decomposition, which will permit identification when the innovation vector is non-normal.

Hafner and Herwartz adopt a multivariate $\operatorname{GARCH}(p, q)$ model framework, given by:

$$
\operatorname{vech}\left(\sum_{t}\right)=c+\sum_{i=1}^{q} A_{i} \operatorname{vech}\left(\varepsilon_{t-i} \varepsilon_{t-i}^{\prime}\right)+\sum_{j=1}^{p} B_{j} \operatorname{vech}\left(\sum_{t-i}\right)
$$

and use the BEKK model of Baba et al. (1985) and Engle and Kroner (1995), which is a special case of equation (8), and is specified as:

$$
\sum_{t}=C_{0} C_{0}^{\prime}+\sum_{k=1}^{K} \sum_{i=1}^{q} A_{k i}^{\prime} \varepsilon_{t-i} \varepsilon_{t-i}^{t} A_{k i}+\sum_{k=1}^{K} \sum_{i=1}^{p} G_{k i}^{\prime} \sum_{t-i} G_{k i}
$$

In equation (9), $C_{0}$ is a lower triangular matrix, and $A_{k i}$ and $G_{k i}$ are $N \times N$ parameter matrices.

\subsection{Volatility Impulse Response Functions}

Hafner and Herwartz (2006) proceed by assuming that, at time $t$, some independent news is reflected in $\xi_{0}$, and it is not specified whether the news is good or bad. The conditional covariance matrix, $\sum_{t}$, is a function of the innovations, $\xi_{1}, \ldots . ., \xi_{t-1}$, the original shock, ${ }{ }$, and $\sum_{0}{ }^{\circ}$ Hafner and Herwartz 
define VIRF as the expectation of volatility conditional on an initial shock and on history, minus the baseline expectation that only conditions on history, as given in the following:

$V_{t}\left(\xi_{0}\right)=E\left\lfloor\operatorname{vech}\left(\sum_{t}\right) \mid \xi_{0}, F_{-1}\right\rfloor-E\left[\operatorname{vech}\left(\sum_{t}\right) \mid F_{-1}\right\rfloor$

In equation (10), $V_{t}\left(\xi_{0}\right)$ is an $N^{*}$-dimensional vector.

Hafner and Herwartz consider a VARMA representation of a multivariate $\operatorname{GARCH}(p, q)$ model in order to find an explicit expression for $V_{t}\left(\xi_{0}\right)$, and define $\eta_{t}=v e c h\left(\varepsilon_{t} \varepsilon_{t}\right)$. They define the multivariate $\operatorname{GARCH}(p, q)$ model as a $\operatorname{VARMA}(\max (p, q), p)$ model:

$\eta_{t}=\omega+\sum_{i=1}^{\max (p, q)}\left(A_{i}+B_{i}\right) \eta_{t-i}-\sum_{j=1}^{p} B_{j} u_{t-j}+u_{t}$

$u_{\text {where }} u_{t}=\eta_{t}-\operatorname{vech}\left(\sum_{t}\right)$ is a white noise vector. From equation (11), Hafner and Herwartz derive the $\operatorname{VMA}(\infty)$ specification, as follows:

$$
\eta_{t}=\operatorname{vech}\left(\sum\right)+\sum_{i=0}^{\infty} \phi_{i} u_{t-i}
$$

where the $N^{*} \times N^{*}$ matrices $\phi_{i}$ can be determined recursively. The general expression for VIRF is:

$V_{t}\left(\xi_{0}\right)=\phi_{t} D_{N}^{+}\left(\sum_{0}^{1 / 2} \otimes \sum_{0}^{1 / 2}\right) D_{N} \operatorname{vech}\left(\xi_{0} \xi_{0}^{\prime}-I_{N}\right)$

Hafner and Herwartz (2006) consider a variety of specifications for the baseline shock. The behaviour implied by equation (13) is different from traditional impulse response analysis. In (13), the impulse is an even, not odd, function of the shock, it is not linear in the shock, and the VIRF depends on the history of the process, although this is via the volatility state at the time the shock occurs. The decayor persistence is given by the moving average matrices, ${ }_{t}$, which is similar to traditional impulse response analysis.

Further complications arise from the choice of baseline because no natural baseline exists for $\varepsilon_{0}^{0}$ in VIRF, as any given baseline deviates from the average volatility state. For example, a zero baseline would represent the lowest volatility state and volatility forecasts would increase from this baseline. After discussing various alternatives, Hafner and Herwartz (2006) adopt the definition given in equation (10). In their original analysis of exchange rates, Hafner and Herwartz examine the impact of particular historical shocks that occur in their sample, as well as considering random shocks for their estimated model.

In an empirical analysis of US and UK indices,weconsider the onset of the GFC, which we date as 9 August 2007 (GFC1), then the date when the financial crisis came to a head, 15 September 2008, when the US government allowed the investment bank Lehman Brothers to go bankrupt (GFC2). The date 9 May 2010 marked the point at which the focus of concern switched from the private sector to the public sector, and this marks the onset of the European Sovereign Debt Crisis (ESDC). We also consider random shocks in the empirical analysis. 


\subsection{Multivariate GARCH Models}

The analysis in the paper features applications of both the BEKK and Diagonal BEKK (DBEKK) models. The BEKK model was introduced by Baba et al. (1985) and Engle and Kroner (1995). In the case of a model with single lags, the BEKK recursion is:

$$
H_{t}=C C^{\prime}+A^{\prime} u_{t-1} u_{t-1}^{\prime} A+B^{\prime} H_{t-1} B
$$

where $H$ is a matrix of the covariances, and $C, A$ and $B$ are the coefficient matrices. The expression above is written in vechformat to generate the VIRFs, as shown below:

$$
\operatorname{vec}\left(H_{t}\right)=\operatorname{vec}\left(C C^{\prime}\right)+\left(A^{\prime} \otimes A^{\prime}\right) \operatorname{vec}\left(u_{t-1} u_{t-1}^{\prime}\right)+\left(B^{\prime} \otimes B^{\prime}\right) \operatorname{vec}\left(H_{t-1}\right) .
$$

However, a drawback of using the BEKK model is that there are no regularity conditions or statistical properties for full BEKK, as discussed in the next subsection. Chang et al. (2015) discuss stochastic processes for univariate and multivariate conditional volatility models, and the following subsections 2.3-2.5 draw closely on their analysis.

The original multivariate extension of univariate GARCH is given in Baba et al. (1985) and Engle and Kroner (1995), while a consideration of leverage effects and the multivariate extension of univariate GJR is given in McAleer et al. (2009). The asymmetry conditions for multivariate GJR are given in the VARMA-AGARCH model of McAleer et al. (2009). Leverage has typically been presented for individual equations only, as defined by Black (1976) for univariate processes using arguments based on the debt-to-equity ratio.

In order to establish volatility spillovers in a multivariate framework, it is useful to define the multivariate extension of the relationship between the returns shocks and the standardized residuals, that is:

$\eta_{t}=\varepsilon_{t} / \sqrt{h_{t}}$

where ${ }^{h_{t}}$ denotes univariate conditional volatility. A multivariate extension of an equation for the conditional mean of financial returns can be written as:

$$
y_{t}=E\left(y_{t} \mid I_{t-1}\right)+\varepsilon_{t},
$$

if it is assumed that the three components are $m \times 1$ vectors, where $m$ is the number of financial assets. The multivariate definition of the relationship between ${ }^{\varepsilon_{t}}$ and $\eta_{t}$ is given as:

$$
\varepsilon_{t}=D_{t}^{1 / 2} \eta_{t}
$$

where $D_{t}=\operatorname{diag}\left(h_{1 t}, h_{2 t}, \ldots, h_{m t}\right)$ is a diagonal matrix comprising the univariate conditional volatilities. Define the conditional covariance matrix of ${ }^{\varepsilon_{t}}$ as $Q_{t}$. As the $m \times 1$ vector, ${ }^{\eta_{t}}$, is assumed to be $i i d$ for all $m$ elements, the conditional correlation matrix of $\eta_{t}$, which is equivalent to the conditional correlation matrix of $\eta_{t}$, is given by $\Gamma_{t}$. Therefore, the conditional expectation of (16) is defined as:

$$
Q_{t}=D_{t}^{1 / 2} \Gamma_{t} D_{t}^{1 / 2}
$$


Equivalently, the conditional correlation matrix, ${ }^{\Gamma_{t}}$, can be defined as:

$$
\Gamma_{t}=D_{t}^{-1 / 2} Q_{t} D_{t}^{-1 / 2}
$$

Equation (17) is useful if a model of $\Gamma_{t}$ is available for purposes of estimating $Q_{t}$, whereas equation (18) is useful if a model of $Q_{t}$ is available for purposes of estimating $\Gamma_{t}$.

Both equations (17) and (18) are instructive for a discussion of asymptotic properties. As the elements of $D_{t}$ are consistent and asymptotically normal, the consistency of $Q_{t}$ in equation (17) depends on consistent estimation of $\Gamma_{t}$, whereas the consistency of $\Gamma_{t}$ in equation (18) depends on consistent estimation of $Q_{t}$. As both $Q_{t}$ and $\Gamma_{t}$ are products of matrices, neither the QMLE of $Q_{t}$ or $\Gamma_{t}$ will be asymptotically normal based on the definitions given in equations (17) and (18).

\subsection{Triangular, Hadamard and Full BEKK}

Without actually deriving the model from an appropriate stochastic process, Baba et al. (1985) and Engle and Kroner (1995) considered the full BEKK model, as well as the special cases of triangular and Hadamard (element-by-element multiplication) BEKK models. The specification of the multivariate model is the same as the specification in equation (14), namely:

$$
H_{t}=C C^{\prime}+A^{\prime} u_{t-1} u_{t-1}^{\prime} A+B^{\prime} H_{t-1} B,
$$

except that A and B are full, Hadamard or triangular matrices.

Although estimation of the full, Hadamard and triangular BEKK models is available in some standard econometric and statistical software packages, it is not clear how the likelihood functions might be determined. Moreover, the so-called "curse of dimensionality", whereby the number of parameters to be estimated is excessively large, makes convergence of any estimation algorithm somewhat problematic.

Jeantheau (1998) showed that the QMLE of the parameters of the full BEKK model is consistent under a multivariate log-moment condition, while Comte and Lieberman (2003) showed that the QMLE are asymptotically normal under the assumption of the existence of eighth moments. Specifically, the multivariate $\log$-moment conditions are difficult to verify when the matrices $A$ and $B$ are neither diagonal nor scalar matrices, and the eighth moment condition cannot be verified for a full BEKK model. Therefore, there are as yet no verifiable asymptotic properties of the full, Hadamard or triangular BEKK models.

\subsection{Diagonal and Scalar BEKK}

Consider a vector random coefficient autoregressive process of order one:

$$
\varepsilon_{t}=\Phi_{t} \varepsilon_{t-1}+\eta_{t}
$$


where

$\varepsilon_{t}$ and $\eta_{t}$ are $m \times 1$ vectors, and $\Phi_{t}$ is an $m \times m$ matrix of random coefficients, and

$\Phi_{t \sim i i d}(0, A)$

$\eta_{t} \sim i i d^{\left(0, Q Q^{\prime}\right)}$

Technically, a vectorization of a full (that is, non-diagonal or non-scalar) matrix $A$ to vec $A$ can have dimension as high as $m^{2} \times m^{2}$, whereas the half-vectorization of a symmetric matrix $A$ to vech $A$ can have dimension as low as $m(m+1) / 2 \times m(m+1) / 2$.

In a case where $\mathrm{A}$ is either a diagonal matrix or the special case of a scalar matrix, $A=a I_{m}$, McAleer et al. (2008) showed that the multivariate extension of $\operatorname{GARCH}(1,1)$ from equation (20), incorporating an infinite geometric lag in terms of the returns shocks, is given as the diagonal BEKK (DBEKK) or scalar BEKK model, namely:

$Q_{t}=Q Q^{\prime}+A \varepsilon_{t-1} \varepsilon_{t-1}^{\prime} A^{\prime}+B Q_{t-1} B^{\prime}$

where $A$ and $B$ are both either diagonal or scalar matrices.

McAleer et al. (2008) showed that the QMLE of the parameters of the diagonal or scalar BEKK models were consistent and asymptotically normal, so that standard statistical inference on testing hypotheses is valid. Moreover, as $Q_{t}$ in equation (21) can be estimated consistently, $\Gamma_{t}$ in equation (18) can also be estimated consistently.

Given the above considerations, we present the results of both full BEKK and DBEKK in the empirical analysis that follows. We can be confident about the statistical properties of DBEKK when it is used to calculate VIRFs, and the important consideration is whether the two methods and their associated VIRFs, have the same implications for our results. If they point to the same conclusions, we can have more confidence in the results.

\section{Empirical results}

Summary statistics for the two sets of series, Oxford-Man RV series for the S\&P500 and the FTSE, for a period beginning 3 January 2000 to $4^{\text {th }}$ October 2016, totaling 4378 observations, and the index return series for the NYSE and the FTSE, for the period 3 January 2005 to 31 December 2014, giving a total of 2608 valid observations, are shown in Table 1. All the series, both the two RV and the two returns series the display excess kurtosis and are skewed, positively in the case of the RV series and negatively in the case of the returns. The time series plots of the index values are shown in Figure 1.

Table 2 provides tests of skewness, kurtosis and whether the return series for the two daily realized volatility series and two index series are normally distributed. The Jarque-Bera (JB) test rejects 
normality at any standard level of significance for all series, and all display significant skewness and excess kurtosis with the exception of the FTSE RV series, which does not show excess kurtosis.

\subsection{Spillover Index Results}

The results of the application of the Diebold Yilmaz (2012) Spillover Index model are shown in Table 3. We experimented with various lag lengths in the VAR but extending the lags beyond 4 did not make an appreciable difference to the Spillover Index results. The Durbin-Watson statistic with a value of 2.03 suggests that serial correlation is not an issue. When the FTSE RV is used as the dependent variable, all the coefficients are highly significant apart from lag 4 on the FTSE RV. If the S\&P500 is the dependent variable, all coefficients are again highly significant with the exception of lag 2 on S\&P500 RV. In this case the Durbin-Watson statistic is 2.04 and the F statistics for both equations is highly significant. We can therefore proceed to the Spillover Index analysis with confidence.

Table 4 presents details of the Spillovers across the two series. The results for the daily RV series for the two series, S\&P500 and the FTSE are reasonably symmetric. Shocks to the S\&P500 RV explain $83.52 \%$ of its own variability, in the generalized forecast error decompositions, whilst contributions from the FTSE RV series explain $16.5 \%$ of its variability. On the reverse side of the coin, the FTSE RV series explains $79.78 \%$ of its own variability with a contribution from the S\&P500 RV of $20.2 \%$.

However, these are average results across the whole sample period.

To further sharpen the results, we followed Diebold and Yilmaz (2012) and estimated volatility spillovers using 200-day rolling samples, which permits the assessment of the extent and the nature of spillover variation over time via the corresponding time series of spillover indices, which are presented

graphically in the so-called total spillover plot of Figure 2. It can be seen that there are peaks in spillovers at the height of the GFC in 2008 and in 2010 at the onset of the European Sovereign debt crisis. (We analyse this further in the next section in our VIRF analysis).

Figure 3 shows directional spillovers from the two markets, and we have not included a graph of directional spillovers to the two markets, as this is a mirror image, given that we are dealing with two markets only. Of greater interest is Figure 4 which shows net spillovers as the difference between S\&P500 RV - FTSE RV. Plots below zero on the graph show the periods in which the FTSE RV contributed more to S\&P500 RV than vice-versa. Clearly, the predominant net contribution is from the S\&P500 RV, as most of the graph plots above 0, but there are 5 distinct periods in which the reverse is the case, and notably in 2009-2010 which coincides with the emergence of sovereign debt problems in Europe and again in 2012. The impact of conditional volatility at specific dates will be explored in the next section.

\subsection{Multivariate GARCH analysis}

The presence of excess skewness leads us to employ the Student $t$ distribution which is used in the subsequent GARCH analysis. We filter the return series through an AR(1) process before proceeding to use the subsequent residuals in a multivariate BEKK analysis to generate the VIRF, as in Hafner and Herwartz (2006).

Table 5 shows the results of the application of the filters, and Table 6 gives the diagnostics for the residuals. The application of the AR(1) model appears to whiten the residuals, and the Ljung-Box Q statistics for serial correlation suggest that correlation is not a problem. The Jarque-Bera (JB) test strongly rejects normality for the shocks, so we conduct the subsequent analysis using the $\mathrm{t}$-distribution. 


\subsection{Results from BEKK analysis}

Table 7 shows the results of the application of the BEKK model. We can forecast the volatility and correlations for the two series using the BEKK model. We forecast for 100 days at the end of the time series and use a window of 400 daily observations to fit the model. The results are shown in Figure 5. The recent experience of relatively high volatilities cause the increase in the two forecast volatilities, while the correlation tends towards the mean over the sub-sample.

Plots of the VIRFs are shown in Figure 6, Panels A and B. The VIRF impulse responses for 9 August 2007, as shown in Panel A, use the variance at that point in time as the baseline. The initial response for the NYSE is scaled at just under 10000. When this is compared to the impulse response of the FTSE in the UK, the response is even larger at just over 10000. These have been computed using a baseline of the estimated volatility state, so they are excess over the predicted covariance. They can be contrasted with the impact of the EU debt crisis on 5 May 2010, in which the NYSE initial response is just over 1500, while the FTSE response at the same point in time is nearly 2000, suggesting that, as might be expected, the EU debt crisis had a larger impact in London than it had in New York.

These shocks have been predicted using a baseline of zero. The 2007 shocks take a period of about 6 months to work through, while the 2010 shocks take a longer period of 8-9 months, but this may well reflect the choice of a lower baseline. The covariances show a dramatic spike in response to both shocks but remain higher for longer, in relation to the 2010 shock, possibly in response to the choice of baseline, as mentioned above. Thus, the choice of baseline remains a key issue in the implementation of VIRF analysis.

Panel B of Figure 6 contrasts the 15 September 2008 GFC impact with the 5 May 2010 EU debt crisis once again, and the choice of baselines mirrors that in Panel A. The impact of the shock in 2008, at the height of the GFC, is relatively higher than previously, in both New York and London. On the NYSE it approaches 25000, while on the FTSE it is even higher, approaching 40000, and the shocks in both markets take longer to die out than they did in 2007, taking 9 months to return to equilibrium. The covariance approaches 20000 and remains at high levels for 6-7 months. The 5 May 2010 graphs are the same as in Panel A, and are included for the purpose of a direct comparison.

Given that we are considering VIRF in the context of stock market indices, it seems appropriate to consider asymmetry effects via the introduction of the separate consideration of the impact of negative shocks. The estimates of the BEKK and asymmetric BEKK-t models are shown in Tables 7 and 9, and the eigenvalues from BEKK-t and asymmetric BEKK-t are given in Tables 8 and 10, respectively (for the sake of brevity, only the multivariate GARCH and asymmetric terms are reported in the tables). The analysis is broadly similar as described above.

Figure 6 shows the VIRF (for the sake of brevity only September 2008 and May 2010 are considered). The key difference in the results, when compared to the previous analysis, is that the VIRFs are larger and of shorter duration. For example, the NYSE variance increases to 8000 and the FTSE variance increases to 15,000 in September 2008. The duration of the response for both 2008 and 2010 is reduced to 3 months for both the variances and covariances.

However, in Section 2.3 in this paper noted that we can be confident about the statistical properties of DBEKK when it is used to calculate VIRFs, which is not the case for full BEKK. The key finding is whether the two methods and their associated VIRFs have the same implications for the empirical results. If the empirical results lead to the same conclusions, we can have greater confidence in the empirical results. In Section 3.2 we present the empirical results and VIRFs from a diagonal BEKK (DBEKK) analysis.

\subsection{Results from DBEKK}

The DBEKK model has valid statistical properties and regularity conditions, so we can be confident in the empirical results. It has to be borne in mind that DBEKK has fewer parameters, so its VIRFs are 
simpler than are those for full BEKK. We estimate DBEKK using the same procedure as discussed previously, and use a t-distribution and include asymmetry.

The asymmetric DBEKK model estimated using a t-distribution (DBEKK-t) is much better behaved, as can be seen in Table 10. All the coefficients apart from one that are shown in Table 5 are significant. The eigenvalues shown in Table 11 are stable, given that all are less than one.

Figure 8 shows the impulse responses generated by the asymmetric DBEKK model estimated using a t distribution (DBEKK-t). The results in Panel A reflect the fact that the 9 August 2007 VIRF has a baseline calculated on the shock at that point in time, while the 15 September 2008 shock has a baseline of zero. The results are consistent with the previous BEKK estimates in that the asymmetric DBEKK model produces negative shocks that last for only 3 months in duration. The 2008 shocks again are larger in LFTSERET than on NYSERET.

Panel B in Figure 8 is constructed in a similar manner. The 9 August 2007 VIRF is calculated on the shock at that point in time, while the 15 September 2008 shock is calculated using a zero baseline. Consistent with the previous results, the shocks have a three-month duration, and their relative sizes are the same as previously calculated, revealing that both the BEKK and DBEKK results are entirely consistent.

In order to complete the analysis, we also calculate a DBEKK model without asymmetries and present the results in Tables 12-13 and in Figure 9. All the coefficients for the DBEKK model, without asymmetries, as shown in Table 12, are highly significant. The eigenvalues, as shown in Table 13, are closer to one than for the DBEKK model with asymmetries, as reported in Table 10, suggesting that the standard BEKK model is less stable.

In Figure 9, for purposes of comparison, we depict the VIRFs for the GFC2 period and the Euro debt crisis. The VIRFs in Figure 9 are consistent with the previous analysis using the full BEKK model without asymmetries. The impact of the 2008 shock is larger in London than in New York, using the shock at that point in time as a baseline. A similar pattern is observed in the 2010 Euro-debt shock. Once again, we observe, ignoring the asymmetries, the duration of the shock is much longer, and now extends to eighteen months in all figures before equilibrium is re-established. This is more than double the durations of the VIRFs recorded for the full BEKK model without asymmetries, but the relative durations remain consistent.

\section{Conclusion}

In this paper we have applied two different methods based on VAR and impulse response analysis to examine volatility spillovers between the New York and the London stock markets. We analysed daily RV estimates taken from the Oxford-Man Realised Library running from the beginning of 2000 to-date using the Diebold and Yilmaz (2012) Spillover Index. The analysis revealed that both the S\&P500 and the FTSE contributed around 20\% in terms of spillovers to the RV of the other market. Figure 2 revealed that total spillovers across the two markets peaked in 2008 and in 2010, whilst Figure 4 showing net spillovers, revealed that though the predominant direction of spillovers was from the S\&P500 RV to the FTSE RV, there were still 5 periods in which the direction of spillovers was reversed, the most recent being in 2010 and 2012. This first portion of the analysis concentrated on RV series, as analysed in a VAR and generalized impulse response framework.

The second portion of the analysis used the Hafner and Herwartz (2006) Volatility Impulse Response Function (VIRF) approach to examine ten years of daily return series from the New York Stock Exchange Index, and the London Stock Exchange FTSE 100 index, for the period 3 January 2005 to 31 January 2015. An attractive feature of VIRF analysis of the effects of shocks on volatility through time is that the shocks are treated as endogenous. In this analysis the focus is on shocks to conditional volatility, as opposed to RV. Given that we are operating in a multivariate GARCH framework, we can accommodate asymmetry effects, and study positive and negative shocks separately, a luxury not afforded by our daily RV series. 
An important difference in this portion of the analysis is that we use a particular point in time for the commencement of our conditional volatility modelling. However, we also note that the choice of the baseline for the shock makes a considerable difference. A useful contribution of this paper is to consider asymmetric effects, which are well documented in the empirical analysis of stock markets (see, for example, Engle and $\mathrm{Ng}$ (1993)). We showed that the impacts of negative shocks are larger, but of shorter duration, than those implied by a symmetric treatment of shocks.

Our empirical analysis is based on application of the full BEKK model, for which no verifiable asymptotic properties exist, as well as the diagonal BEKK (DBEKK) model, which is not so constrained. The empirical results our consistent and suggest that the inclusion of asymmetries is important when VIRF analysis is applied to stock market data. It was found that the responses to negative shocks are deeper and of shorter duration than the responses to positive shocks. The empirical results of both the BEKK and DBEKK models are strongly consistent with each other.

The results of our analysis are not necessarily good news for investors. Volatility spillovers increase in times of crises, making hedging more difficult, and the response is particularly sharp, though more short lived, as revealed by the VIRF analysis, to negative shocks.

\section{References}

Alter, A., and A. Beyer, (2013) The Dynamics of Spillover Effects during the European Sovereign Debt Turmoil, European Central Bank Working Paper Series, No. 1558.

Baba, Y., R.F. Engle, D. Kraft and K.F. Kroner (1985), Multivariate simultaneous generalized ARCH, Unpublished manuscript, Department of Economics, University of California, San Diego, CA, USA.

Black, F. (1976), Studies of stock market volatility changes, in Proceedings of the American Statistical Association, Business and Economic Statistics Section, Washington, DC, USA, 1976, pp. 177-181.

Chang, C.-L. Y.-Y. Li and M. McAleer (2015), Volatility spillovers between energy and agricultural markets: A critical appraisal of theory and practice, Econometric Institute Research Paper EI2015-18, Erasmus School of Economics, Erasmus University Rotterdam.

Comte, F. and O. Lieberman (2003), Asymptotic theory for multivariate GARCH processes, Journal of Multivariate Analysis, 84, 61-84.

Diebold, F.X. and K. Yilmaz, (2009), Measuring Financial Asset Return and Volatility Spillovers, With Application to Global Equity Markets, Economic Journal, 119, 158-171.

Diebold, F.X. and K. Yilmaz, (2012), Better to give than to receive: Predictive directional measurement of volatility spillovers, International Journal of Forecasting, 28(1), 57-66.

Diebold, F.X. and K. Yilmaz, (2014), On the Network Topology of Variance Decompositions: Measuring the Connectedness of Financial Firms, Journal of Econometrics, 182, 119-134.

Diebold, F.X. and K. Yilmaz, (2016), Trans-Atlantic Equity Volatility Connectedness: U.S. and European Financial Institutions, 2004-2014, Journal of Financial Econometrics, 14, 81-127.

Engle, R.F. and V.K. Ng (1993), Measuring and testing the impact of news on volatility, Journal of Finance, 48, 1749-1778

Engle, R.F. and K.F. Kroner (1995), Multivariate simultaneous generalized ARCH, Econometric Theory, 11, 122-150.

Engle, Robert F., Takatoshi Ito and Wen-Ling Lin (1990), Meteor Showers or Heat Waves? Heteroskedastic Intra-Daily Volatility in the Foreign Exchange Market, Econometrica, $58,525-542$. 
Drost, F. and T. Nijman (1993), Temporal aggregation of GARCH processes, Econometrica, 61, 909-927.

Gallant, A.R., P.E. Rossi and G. Tauchen (1993), Nonlinear dynamic structures, Econometrica, 61, 871-907.

Gerd, H., A. Lunde, N. Shephard and K. Sheppard (2009) Oxford-Man Institute's realized library, Oxford-Man Institute, University of Oxford.

Hafner, C.M. and H. Herwartz (2006), Volatility impulse responses for multivariate GARCH models: An exchange rate illustration, Journal of International Money and Finance, 25, 719-740.

Jeantheau, T. (1998), Strong consistency of estimators for multivariate ARCH models, Econometric Theory, 14, 70-86.

Jin, X., S.X. Lin, and M. Tamvakis, (2012). Volatility transmission and volatility impulse response functions in crude oil markets, Energy Economics, 34(6), 2125-2134.

Kloessner, S. and S. Wagner, (2012): Exploring All VAR Orderings for Calculating Spillovers? Yes, We Can! - A Note on Diebold and Yilmaz (2009), Journal of Applied Econometrics, 29 (1), $172-179$

Koop, G., M.H. Pesaran and S.M. Potter (1996). Impulse response analysis in nonlinear multivariate models. Journal of Econometrics, 74, 119-147.

Koutmos, G. and G.G. Booth (1995), Asymmetric volatility transmission in international stock markets, Journal of International Money and Finance, 14, 747-762.

Le Pen, Y., B. Sévi, (2010), Volatility transmission and volatility impulse response functions in European electricity forward markets, Energy Economics, 32(4), 758-770.

Lin, W.-L. (1997), Impulse response function for conditional volatility in GARCH models, Journal of Business \& Economic Statistics, 15, 15-25.

McAleer, M., S. Hoti and F. Chan (2009), Structure and asymptotic theory for multivariate asymmetric conditional volatility, Econometric Reviews, 28, 422-440.

Olson, E., A.J. Vivian, and M.E. Wohar, (2014), The relationship between energy and equity markets: Evidence from volatility impulse response functions. Energy Economics, 43, 297-305.

Panopoulou, E., and T. Pantelidis, (2009) Integration at a cost: evidence from volatility impulse response functions, Applied Financial Economics, 19(11), 917-933.

Pesaran, M.H. and Shin, Y. (1998), Generalized Impulse Response Analysis in Linear Multivariate Models, Economics Letters, 58, 17-29.

Ross, S.A. (1989), Information and volatility: The no-arbitrage Martingale approach to timing and resolution irrelevancy, Journal of Finance, 44, 1-17

Sims, C. (1980), Macroeconomics and reality, Econometrica 48, 1-48.

Tauchen, G., H. Zhang, and M. Liu (1996), Volume, volatility and leverage: A dynamic analysis, Journal of Econometrics, 74, 177-208. 


\begin{tabular}{|c|c|c|c|}
\hline \multicolumn{4}{|c|}{ Table 1} \\
\hline \multicolumn{4}{|c|}{$\begin{array}{c}\text { Summary Statistics, using the observations 2000-01-03 - 2016-10-04 } \\
\text { for the variable SP500rv10 (4307 valid observations) }\end{array}$} \\
\hline Mean & Median & Minimum & Maximum \\
\hline 0.000123594 & $5.71766 \mathrm{e}-005$ & $1.58546 \mathrm{e}-006$ & 0.00778409 \\
\hline Std. Dev. & C.V. & Skewness & Ex. kurtosis \\
\hline 0.000263820 & 2.13457 & 10.5658 & 205.991 \\
\hline $5 \%$ Perc. & $95 \%$ Perc. & IQ range & Missing obs. \\
\hline $1.14322 \mathrm{e}-005$ & 0.000412656 & $9.19428 \mathrm{e}-005$ & 2 \\
\hline \multicolumn{4}{|c|}{$\begin{array}{c}\text { Summary Statistics, using the observations 2000-01-03 - 2016-10-04 } \\
\text { for the variable FTSErv10 (4309 valid observations) }\end{array}$} \\
\hline Mean & Median & Minimum & Maximum \\
\hline 0.000137715 & $7.92406 \mathrm{e}-005$ & $4.80005 \mathrm{e}-006$ & 0.00391275 \\
\hline Std. Dev. & C.V. & Skewness & Ex. kurtosis \\
\hline 0.000208074 & 1.51090 & 6.56405 & 73.2867 \\
\hline $5 \%$ Perc. & $95 \%$ Perc. & IQ range & Missing obs. \\
\hline $1.64529 \mathrm{e}-005$ & 0.000425980 & 0.000114844 & 0 \\
\hline \multicolumn{4}{|c|}{ Summary Statistics for 2005-01-03 - 2014-12-31 (2608 valid observations) } \\
\hline \multicolumn{4}{|c|}{ NYSERET (2608 valid observations) } \\
\hline Mean & Median & Minimum & Maximum \\
\hline 0.000154204 & 0.000431926 & -0.102321 & 0.115258 \\
\hline Std. Dev. & C.V. & Skewness & Ex. kurtosis \\
\hline 0.0133989 & 86.8909 & -0.417694 & 10.8634 \\
\hline $5 \%$ Perc. & $95 \%$ Perc. & IQ range & Missing obs. \\
\hline-0.0202854 & 0.0179030 & 0.0103402 & 0 \\
\hline \multicolumn{4}{|c|}{ Summary Statistics for 2005-01-03 - 2014-12-31 (2608 valid observations) } \\
\hline \multicolumn{4}{|c|}{ FTSERET } \\
\hline Mean & Median & Minimum & Maximum \\
\hline $3.92100 \mathrm{e}-005$ & 0.000475224 & -0.105381 & 0.122189 \\
\hline Std. Dev. & C.V. & Skewness & Ex. kurtosis \\
\hline 0.0148037 & 377.549 & -0.110113 & 9.87695 \\
\hline $5 \%$ Perc. & $95 \%$ Perc. & IQ range & Missing obs. \\
\hline-0.0227705 & 0.0205110 & 0.0132403 & 0 \\
\hline
\end{tabular}


Table 2

Tests of Skewness, Excess Kurtosis, and Normality, Base Series

\begin{tabular}{|c|c|c|}
\hline S\&P500 RV & & \\
\hline Skewness & 0.408550 Signif Level $(\mathrm{Sk}=0) \quad 0.0$ & \\
\hline Kurtosis (excess) & 0.313096 Signif Level $(\mathrm{Ku}=0)$ & 0.000028 \\
\hline Jarque-Bera & 12954.814995Signif Level $(\mathrm{JB}=0)$ & 0.0 \\
\hline FTSERET RV & & \\
\hline Skewness & 0.242345Signif Level $(\mathrm{Sk}=0)$ & \\
\hline Kurtosis (excess) & -0.072373Signif Level $(\mathrm{Ku}=0)$ & 0.332565 \\
\hline Jarque-Bera & 43.119157Signif Level $(\mathrm{JB}=0)$ & 0.0 \\
\hline NYSERET $(* 100)$ & & \\
\hline Skewness & Signif Level $(\mathrm{Sk}=0)$ & 0.0 \\
\hline Kurtosis (excess) & Signif Level $(\mathrm{Ku}=0)$ & 0.0 \\
\hline Jarque-Bera & Signif Level $(J B=0)$ & 0.0 \\
\hline FTSERET $(* 100)$ & & \\
\hline Skewness & Signif Level $(\mathrm{Sk}=0)$ & 0.021693 \\
\hline Kurtosis (excess) & Signif Level $(\mathrm{Ku}=0)$ & 0.0 \\
\hline Jarque-Bera & Signif Level $(\mathrm{JB}=0)$ & 0.0 \\
\hline
\end{tabular}


Table 3 VAR analysis of RV Series

VAR/System - Estimation by Least Squares

Daily(5) Data From 2000:01:07 To 2016:07:07

Usable Observations 4305

Dependent Variable SP500RV

Mean of Dependent Variable $\quad-9.717844778$

Std Error of Dependent Variable 1.106068769

Standard Error of Estimate $\quad 0.638009300$

Sum of Squared Residuals $\quad 1748.7120061$

Durbin-Watson Statistic $\quad 2.0273$

$\begin{array}{lrrrr}\text { Variable } & \text { CoeffStd Error } & \text { T-Stat } & \text { Signif } \\ \text { *************************************************************************************** } \\ \text { 1. SP500RV }\{1\} & 0.369228436 & 0.015969475 & 23.12089 & 0.00000000 \\ \text { 2. SP500RV }\{2\} & 0.217602857 & 0.016798795 & 12.95348 & 0.00000000 \\ \text { 3. SP500RV }\{3\} & 0.108657867 & 0.016779418 & 6.47566 & 0.00000000 \\ \text { 4. SP500RV }\{4\} & 0.154975784 & 0.016092016 & 9.63060 & 0.00000000 \\ \text { 5. FTSERV }\{1\} & 0.141650177 & 0.018892250 & 7.49779 & 0.00000000 \\ \text { 6. FTSERV }\{2\} & -0.045139245 & 0.019999553 & -2.25701 & 0.02405731 \\ \text { 7. FTSERV }\{3\} & -0.045568212 & 0.020026164 & -2.27543 & 0.02292896 \\ \text { 8. FTSERV }\{4\} & 0.017123961 & 0.018739773 & 0.91378 & 0.36088565 \\ \text { 9. Constant } & -0.811716415 & 0.105384744 & -7.70241 & 0.00000000\end{array}$

F-Tests, Dependent Variable SP500RV

\begin{tabular}{lcc}
\multicolumn{1}{c}{ Variable } & F-Statistic & Signif \\
$* * * * * * * * * * * * * * * * * * * * * * * * * * * * * * * * * * * * * * * * * * * * * * * * * * * * * * *$ & 0.0000000 \\
SP500RV & 896.7972 & 0.000000 \\
FTSERV & 16.7243 & 0.0000000
\end{tabular}

Dependent Variable FTSERV

Mean of Dependent Variable $\quad-9.434120085$

Std Error of Dependent Variable 1.003790906

Standard Error of Estimate $\quad 0.539330643$

Sum of Squared Residuals $\quad 1249.6099216$

Durbin-Watson Statistic $\quad 2.0416$

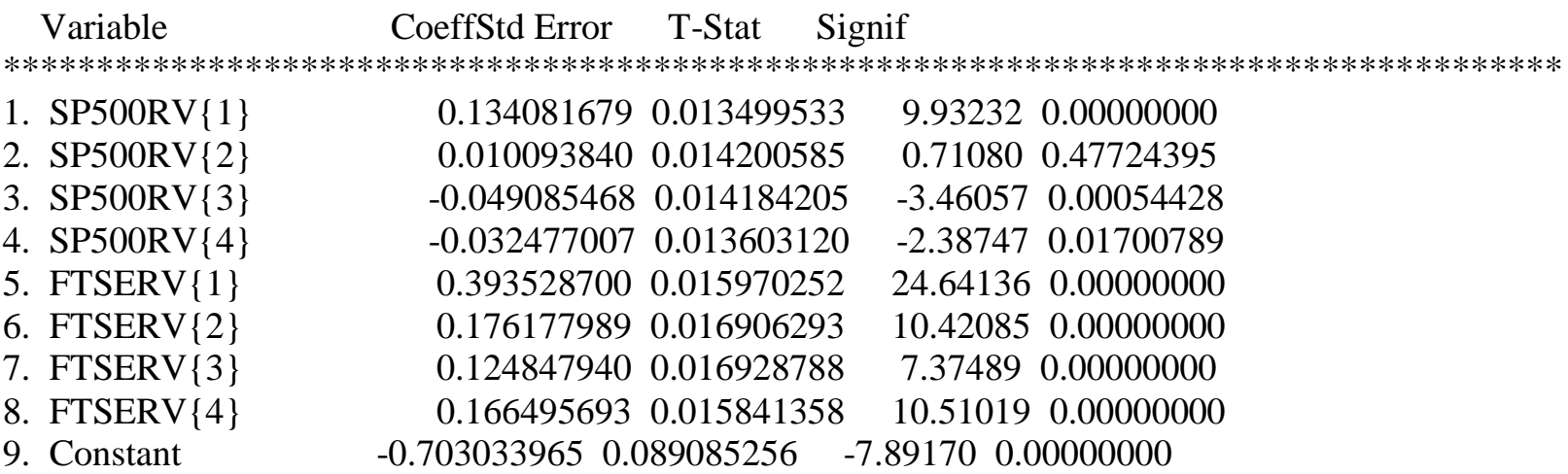

F-Tests, Dependent Variable FTSERV Variable F-Statistic Signif

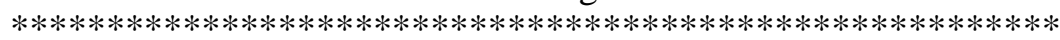

$\begin{array}{lcc}\text { SP500RV } & 29.8631 & 0.0000000 \\ \text { FTSERV } & 1081.5072 & 0.0000000\end{array}$


Table 4 Spillover Index

\begin{tabular}{|c|c|c|c|}
\hline SP500 RV & SE RV & From Others & \\
\hline SP500 RV & 83.52 & 16.48 & 16.5 \\
\hline FTSE RV & 20.22 & 79.78 & 20.2 \\
\hline Contribution to others & 20.2 & 16.5 & 36.7 \\
\hline
\end{tabular}

Table 5

$\operatorname{AR}(1)$ and preliminary $\operatorname{GARCH}(1,1)$ analysis of return series

\begin{tabular}{|l|l|l|l|}
\hline NYSE & & & \\
\hline Variables & Coefficient & t-statistic & Significance \\
\hline Constant & 0.054269041 & 3.39885 & 0 \\
\hline LNYSERET(1) & -0.050346740 & -2.49472 & 0.013 \\
\hline GARCH(1,1) & & & \\
\hline C & 0.016988318 & 2.95313 & 0.003 \\
\hline A & 0.093671095 & 6.40479 & 0 \\
\hline B & 0.893694731 & 61.55474 & 0 \\
\hline FTSE & & & \\
\hline Constant & $4.7248 \mathrm{e}-004$ & 2.35012 & 0.019 \\
\hline LFTSERET(1) & -0.0463 & -2.27302 & 0.023 \\
\hline C & $1.7113 \mathrm{e}-006$ & 2.90809 & 0 \\
\hline A & 0.0911 & 5.66440 & 0 \\
\hline B & 0.9013 & 52.15142 & 0 \\
\hline
\end{tabular}

Table 6

\section{Residual diagnostics}

\begin{tabular}{|l|l|l|l|}
\hline ARCH-LM(1) & JB & $\mathbf{Q ( 1 0 )}$ & $\mathbf{Q ( 2 0 )}$ \\
\hline LNYSERET & & & \\
\hline $8.476(0.004)$ & $472.482(0.000)$ & $9.000(0.437)$ & $23.055(0.235)$ \\
\hline LFTSERET & & & \\
\hline $0.002(0.967)$ & $197.09(0.000)$ & $5.125(0.823)$ & $17.914(0.528)$ \\
\hline
\end{tabular}


Table 7

BEKK

\begin{tabular}{|l|l|l|l|l|}
\hline Variable & Coefficient & $\begin{array}{l}\text { Standard } \\
\text { Error }\end{array}$ & t-statistic & Significance \\
\hline Constant & 0.094673045 & 0.015120103 & 6.26140 & 0 \\
\hline LNYSERET $\{1\}$ & -0.252211378 & 0.018119393 & -13.91942 & 0 \\
\hline Constant & 0.077323881 & 0.019894664 & 3.88666 & 0 \\
\hline LFTSERET $\{1\}$ & -0.168032092 & 0.016587251 & -10.13020 & 0 \\
\hline C(1,1) & -0.097175963 & 0.044805916 & -2.16882 & 0.03 \\
\hline C(2,1) & -0.264611585 & 0.034032404 & -7.77528 & 0 \\
\hline C(2,2) & -0.000000180 & 0.149309283 & $-1.20715 \mathrm{e}-006$ & 0.999 \\
\hline $\mathrm{A}(1,1)$ & 0.021678144 & 0.041879070 & 0.51764 & 0.605 \\
\hline $\mathrm{A}(1,2)$ & -0.383455482 & 0.052098541 & -7.36020 & 0 \\
\hline $\mathrm{A}(2,1)$ & -0.222393062 & 0.035195693 & -6.31876 & 0 \\
\hline $\mathrm{A}(2,2)$ & -0.063023626 & 0.046314167 & -1.36079 & 0.173 \\
\hline $\mathrm{B}(1,1)$ & 1.202152703 & 0.015121227 & 79.50100 & 0 \\
\hline $\mathrm{B}(1,2)$ & 0.450960714 & 0.027752985 & 16.24909 & 0 \\
\hline $\mathrm{B}(2,1)$ & -0.354541888 & 0.021500835 & -16.48968 & 0 \\
\hline $\mathrm{B}(2,2)$ & 0.591348452 & 0.024731239 & 23.91099 & 0 \\
\hline Shape & 7.670707369 & 0.748939459 & 10.24209 & 0 \\
\hline
\end{tabular}

Table 8

Eigenvalues from BEKK-t

\begin{tabular}{|c|c|c|c|c|c|}
\hline 0.98025 & 0 & 0.72696 & -0.46101 & 0.72696 & 0.46101 \\
\hline Var & JB & p-value & & & \\
\hline 1 & 147.280 & 0 & & & \\
\hline 2 & 69.556 & 0 & & & \\
\hline All & 216.836 & 0 & & & \\
\hline
\end{tabular}


Table 9

Asymmetric BEKK-t

\begin{tabular}{|l|l|l|l|l|}
\hline Variable & Coefficient & $\begin{array}{l}\text { Standard } \\
\text { Error }\end{array}$ & t-statistic & Significance \\
\hline $\mathrm{A}(1,1)$ & -0.022753722 & 0.060798967 & -0.37425 & 0.708 \\
\hline $\mathrm{A}(1,2)$ & -0.405700847 & 0.065933722 & -6.15316 & 0 \\
\hline $\mathrm{A}(2,1)$ & 0.148631275 & 0.035519302 & 4.18452 & 0 \\
\hline $\mathrm{A}(2,2)$ & 0.296233075 & 0.041308360 & 7.17126 & 0 \\
\hline $\mathrm{B}(1,1)$ & 0.812855262 & 0.026787787 & 30.34425 & 0 \\
\hline $\mathrm{B}(1,2)$ & -0.151242974 & 0.031493570 & -4.80234 & 0 \\
\hline $\mathrm{B}(2,1)$ & 0.161414758 & 0.030535132 & 5.28620 & 0 \\
\hline $\mathrm{B}(2,2)$ & 0.997063705 & 0.025611106 & 38.93091 & 0 \\
\hline $\mathrm{D}(1,1)$ & -0.469369500 & 0.036937131 & -12.70725 & 0 \\
\hline $\mathrm{D}(1,2)$ & -0.393521072 & 0.089578341 & -4.39304 & 0 \\
\hline $\mathrm{D}(2,1)$ & 0.211373660 & 0.061407304 & 3.44216 & 0 \\
\hline $\mathrm{D}(2,2)$ & -0.083147397 & 0.085927903 & -0.96764 & 0.333 \\
\hline $\mathrm{Shape}$ & 8.904691765 & 0.951329821 & 9.36026 & 0 \\
\hline
\end{tabular}


Table 10

Asymmetric DBEKK-t

\begin{tabular}{|l|l|l|l|l|}
\hline Variable & Coefficient & $\begin{array}{l}\text { Standard } \\
\text { Error }\end{array}$ & t-statistic & Significance \\
\hline $\begin{array}{l}\text { Mean Model } \\
\text { LNYSERET }\end{array}$ & & & & \\
\hline Constant & 0.072214891 & 0.016514826 & 4.37273 & 0 \\
\hline LNYSERET(1) & -0.246671385 & 0.017309242 & -14.25085 & 0 \\
\hline $\begin{array}{l}\text { Mean Model } \\
\text { LFTSERET }\end{array}$ & & & & \\
\hline Constant & 0.051226153 & 0.019264661 & 2.65907 & 0.008 \\
\hline LFTSERET(1) & -0.129102063 & 0.016647036 & -7.75526 & 0 \\
\hline C(1,1) & 0.122517499 & 0.012861431 & 9.52596 & 0 \\
\hline C(2,1) & 0.110032035 & 0.015744065 & 6.98879 & 0 \\
\hline (2,2) & 0.088019683 & 0.012074757 & 7.28956 & 0 \\
\hline A(1) & -0.024217524 & 0.033245856 & -0.72844 & 0.466 \\
\hline A(2) & -0.150597648 & 0.029857611 & -5.04386 & 0 \\
\hline $\mathrm{B}(1)$ & 0.959878240 & 0.004026069 & 238.41572 & 0 \\
\hline $\mathrm{B}(2)$ & 0.959775221 & 0.005034805 & 190.62807 & 0 \\
\hline $\mathrm{D}(1)$ & 0.338891628 & 0.018669042 & 18.15260 & 0 \\
\hline $\mathrm{D}(2)$ & 0.283093998 & 0.025964433 & 10.90315 & 0 \\
\hline Shape & 7.623084667 & 0.738881477 & 10.31706 & 0 \\
\hline & & & & \\
\hline
\end{tabular}

\section{Table 11}

Eigenvalues from Asymmetric BEKK-t

\begin{tabular}{|l|l|l|}
\hline $0.94383,0$ & $0.92489,0$ & $0.92193,0$ \\
\hline Var & JB & p-value \\
\hline 1 & 153.216 & 0 \\
\hline 2 & 224.941 & 0 \\
\hline All & 378.157 & 0 \\
\hline
\end{tabular}


Table 12

DBEKK-t without Asymmetries

\begin{tabular}{|c|c|c|c|c|}
\hline Variable & Coefficient & $\begin{array}{l}\text { Standard } \\
\text { Error }\end{array}$ & t-statistic & Significance \\
\hline \multicolumn{5}{|l|}{$\begin{array}{l}\text { Mean Model } \\
\text { LNYSERET }\end{array}$} \\
\hline Constant & 0.090305522 & 0.015901813 & 5.67895 & 0 \\
\hline LNYSERET(1) & -0.251500344 & 0.017757663 & -14.16292 & 0 \\
\hline \multicolumn{5}{|l|}{$\begin{array}{l}\text { Mean Model } \\
\text { LFTSERET }\end{array}$} \\
\hline Constant & 0.064511941 & 0.019540751 & 3.30141 & 0.001 \\
\hline LFTSERET(1) & -0.138112219 & 0.016239859 & -8.50452 & 0 \\
\hline $\mathrm{C}(1,1)$ & 0.120332752 & 0.014853367 & 8.10138 & 0 \\
\hline $\mathrm{C}(2,1)$ & 0.079599176 & 0.013060471 & 6.09466 & 0 \\
\hline $\mathrm{C}(2,2)$ & 0.092005900 & 0.013195478 & 6.97253 & 0 \\
\hline $\mathrm{A}(1)$ & 0.281404331 & 0.016505582 & 17.04904 & 0 \\
\hline $\mathrm{A}(2)$ & 0.243537494 & 0.016343016 & 14.90162 & 0 \\
\hline $\mathrm{B}(1)$ & 0.954923410 & 0.005051244 & 189.04719 & 0 \\
\hline $\mathrm{B}(2)$ & 0.966108091 & 0.004134165 & 233.68881 & 0 \\
\hline Shape & 6.754575562 & 0.611797521 & 11.04054 & 0 \\
\hline
\end{tabular}

Table 13

Eigenvalues from BEKK-t

\begin{tabular}{|l|l|l|}
\hline $0.99268,0$ & $0.99109,0$ & $0.99107,0$ \\
\hline Var & JB & p-value \\
\hline 1 & 159.968 & 0 \\
\hline 2 & 240.138 & 0 \\
\hline All & 400.106 & 0 \\
\hline
\end{tabular}


Figure 1 Plots of FTSE and NYSE values, plus S\&P500 and FTES RV

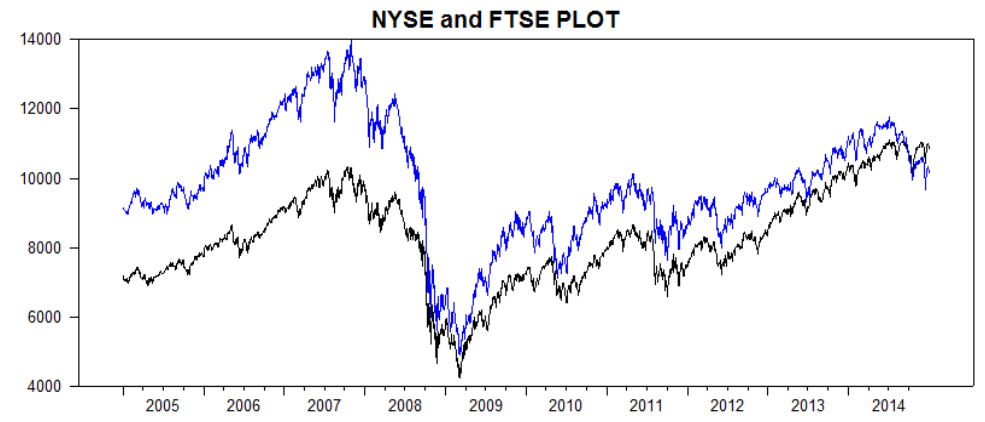

Note: NYSE - Blue, FTSE - Black.

S\&P500 Realised Volatility (RV)

FTSE Realised Volatility (RV)
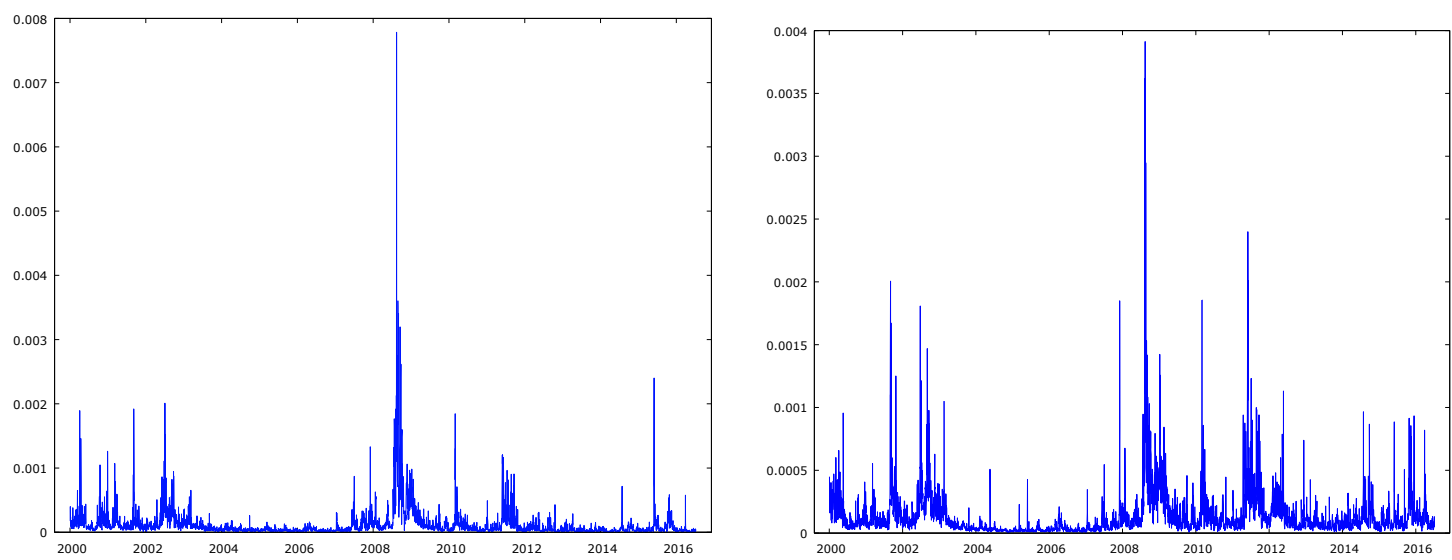

Figure 2. Total Volatility Spillovers, Two Markets

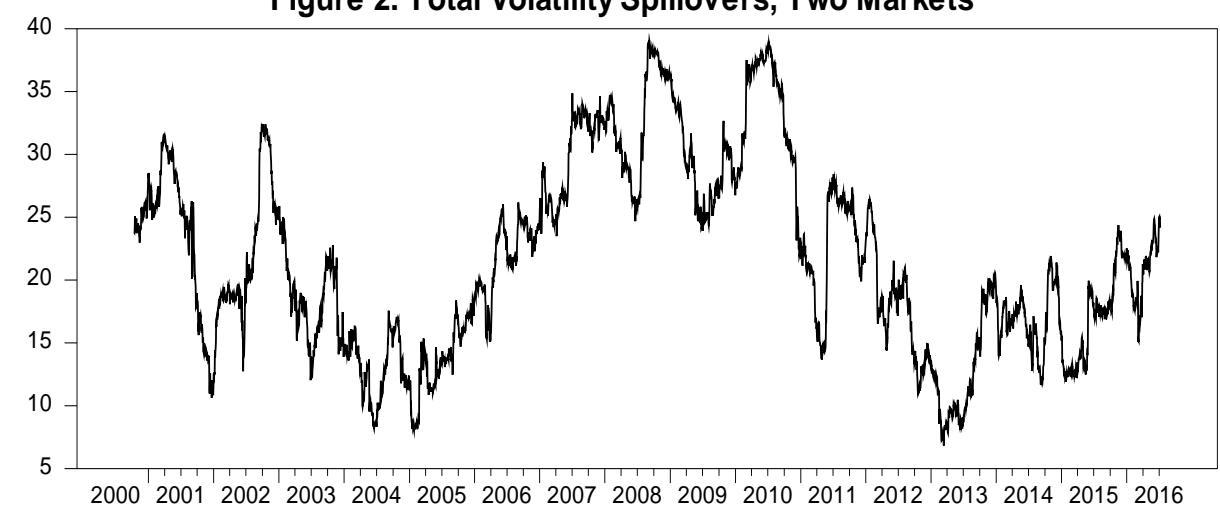


Figure 3. Directional Volatility Spillovers, FROM two Markets

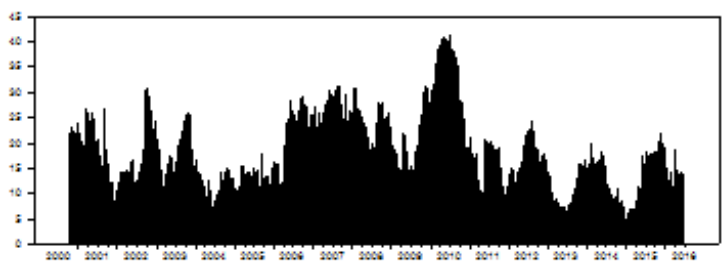

FTIE Rosllsod Volatilit;

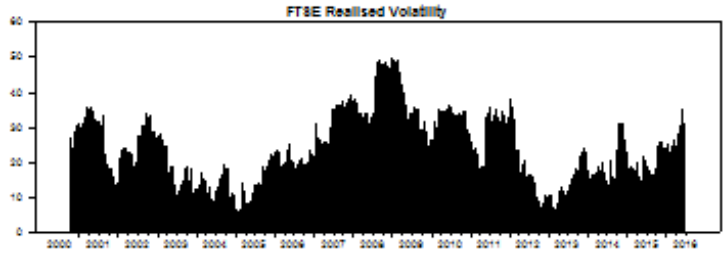

Figure 4 Net Pairwise Volatility Spillovers SP500 RV-FTSE RV

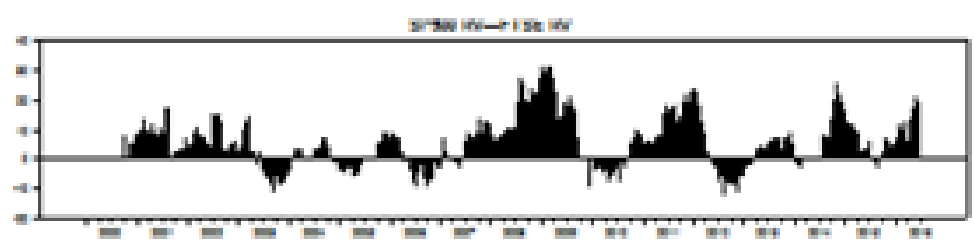

Figure 5100 day forecasts based on BEKK
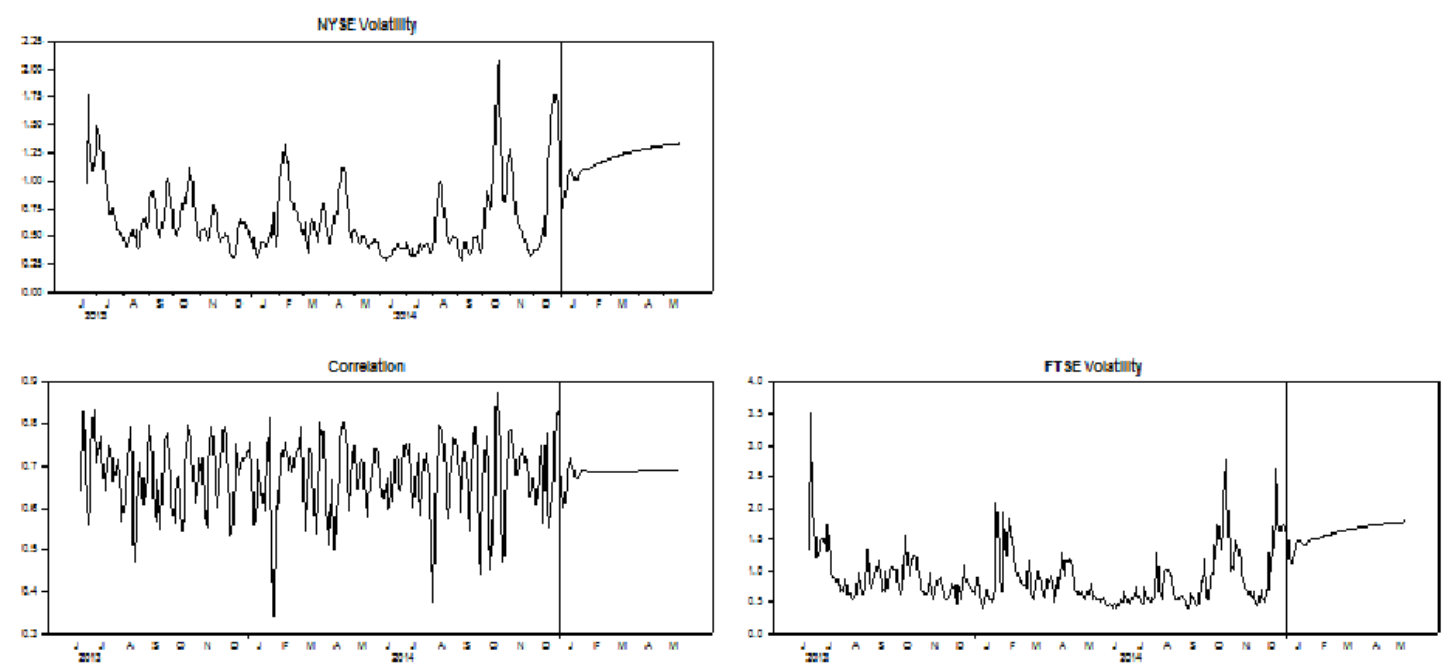
Figure 6 VIRF Panel A: Baselines 9 August 2007 and 5 May 2010

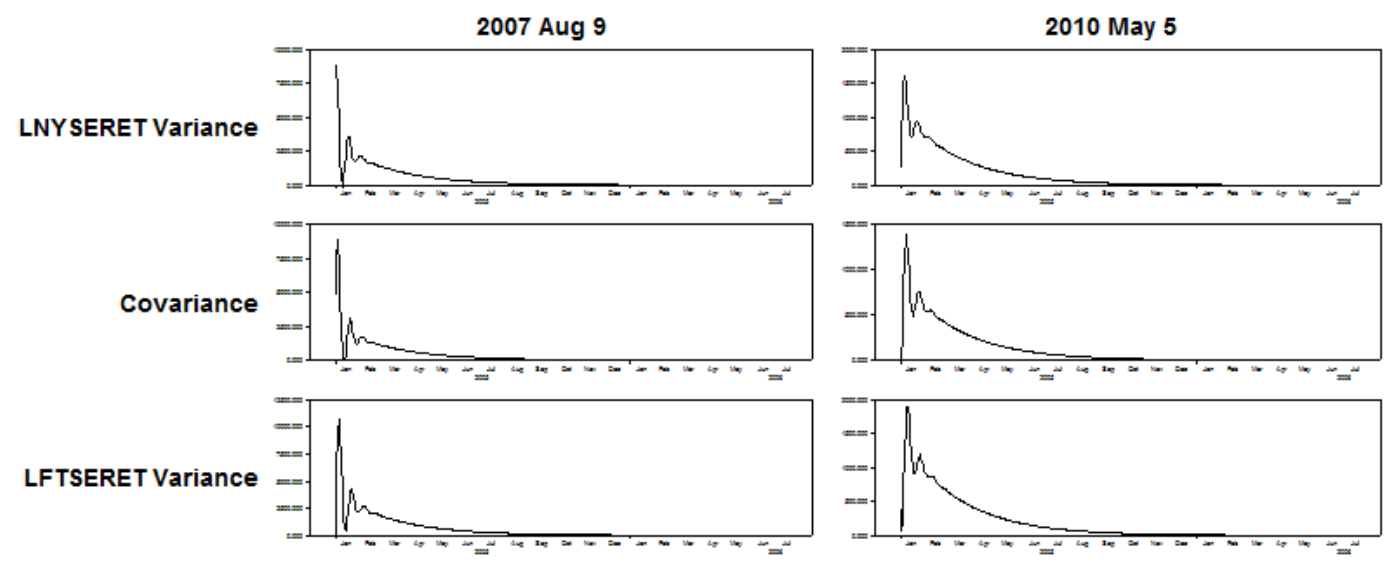

VIRF Panel B: Baselines 15 September 2008 and 5 May 2010
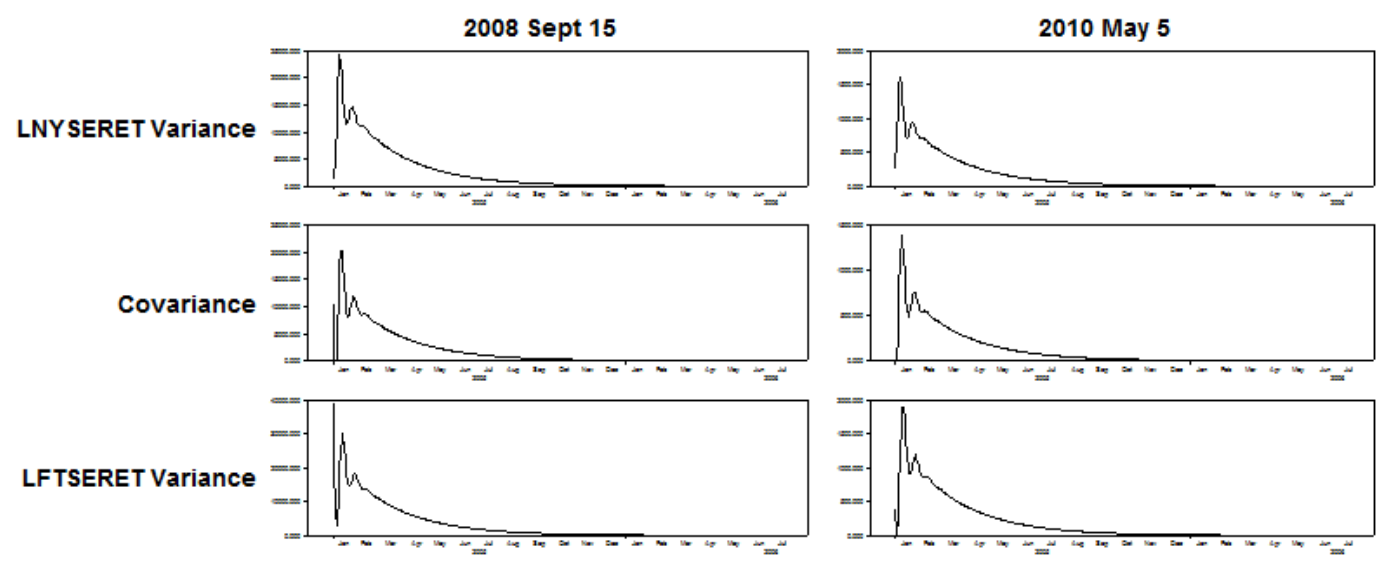

Figure 7 VIRF Asymmetric BEKK (responses to negative price movements)

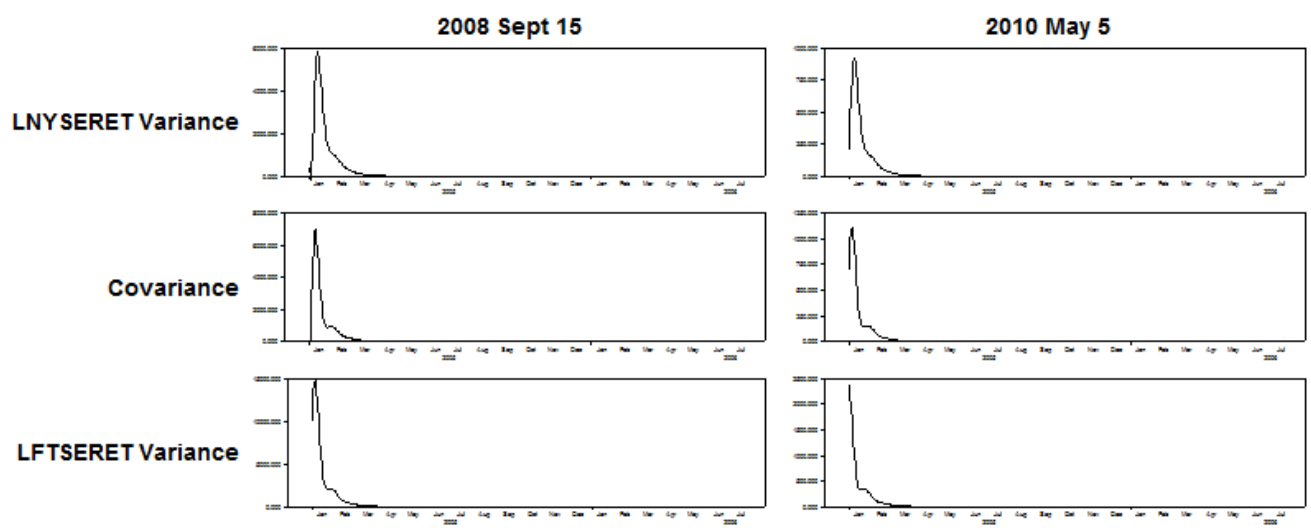


Figure 8 VIRF Asymmetric DBEKK-t

Panel A
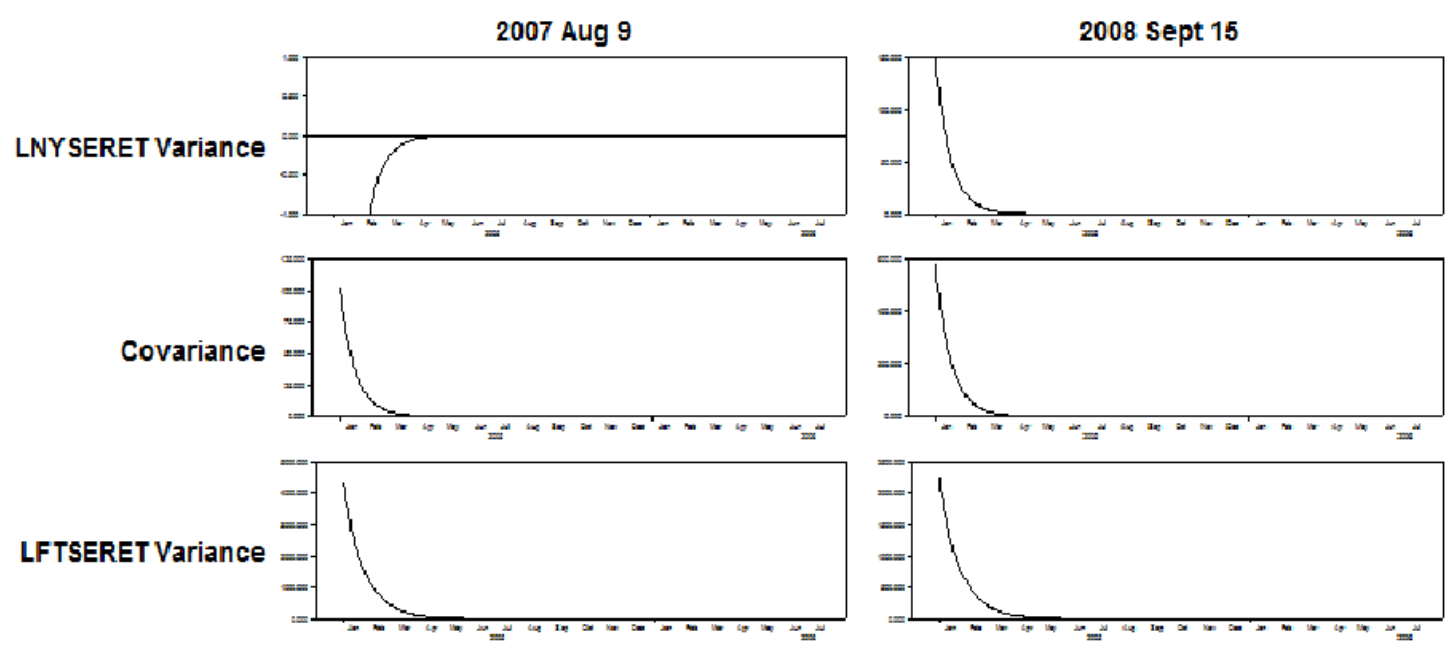

Panel B
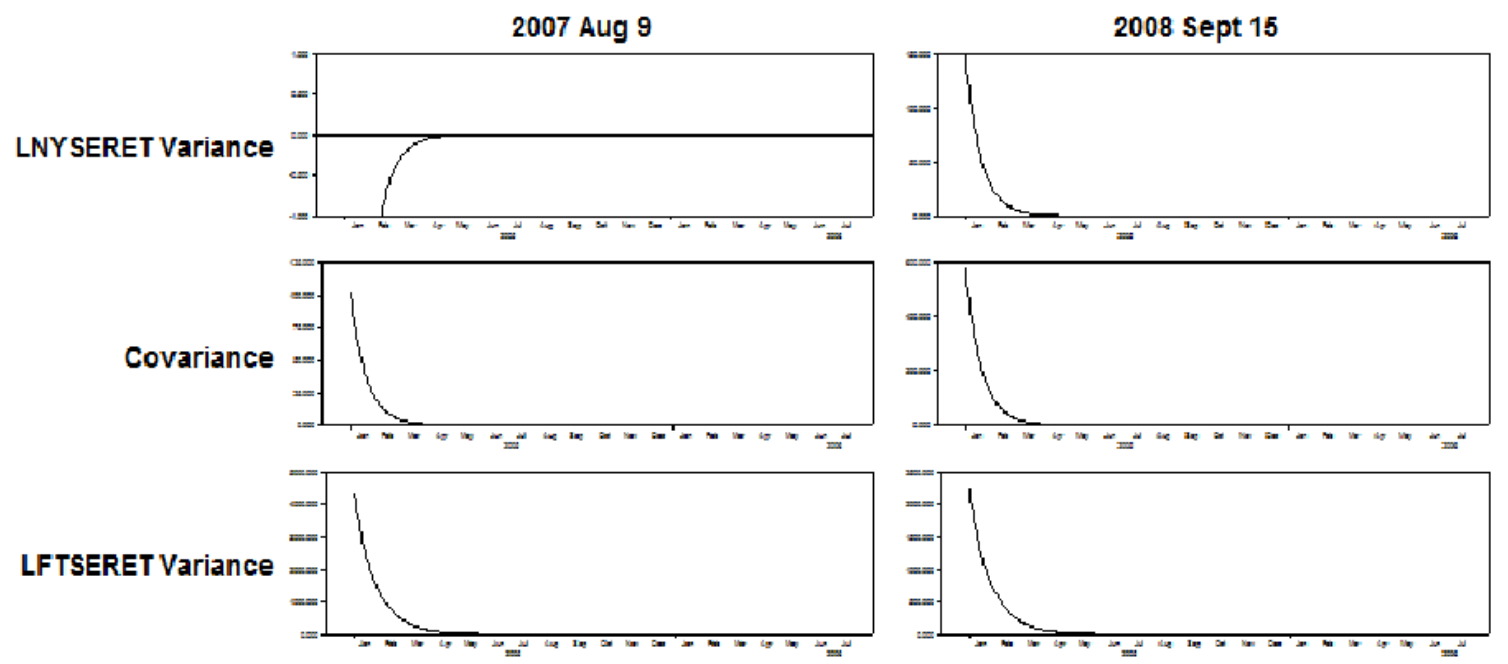

Figure 9 VIRF for GFC2 and Euro Debt crisis using DBEKK-t
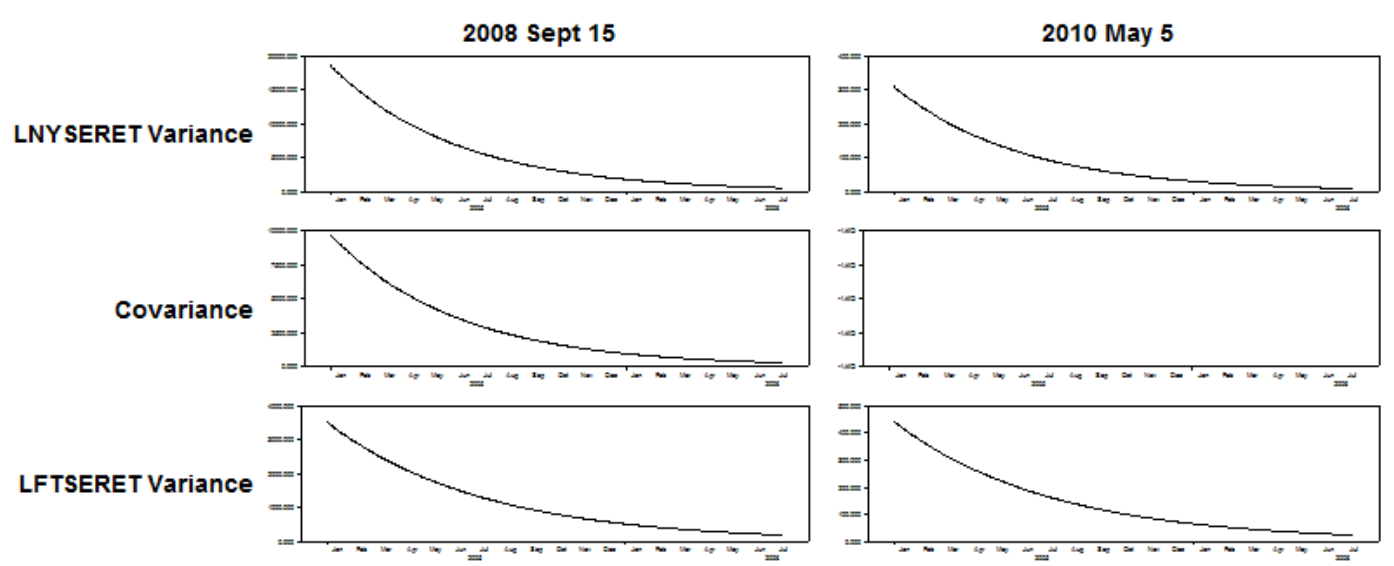